\title{
There is no dilemma for conceptual engineering. Reply to Max Deutsch
}

\author{
Steffen $\operatorname{Koch}^{1}$ (D)
}

Accepted: 13 September 2020/Published online: 18 September 2020

(C) The Author(s) 2020

\begin{abstract}
Max Deutsch (in: Philosophical studies, online-first. https://doi.org/ 10.1007/s11098-020-01416-z, 2020) has recently argued that conceptual engineering is stuck in a dilemma. If it is construed as the activity of revising the semantic meanings of existing terms, then it faces an unsurmountable implementation problem. If, on the other hand, it is construed as the activity of introducing new technical terms, then it becomes trivial. According to Deutsch, this conclusion need not worry us, however, for conceptual engineering is ill-motivated to begin with. This paper responds to Deutsch by arguing, first, that there is a third construal of conceptual engineering, neglected by him, which renders it both implementable and non-trivial, and second, that even the more ambitious project of changing semantic meanings is no less feasible than other normative projects we currently pursue. Lastly, the value of conceptual engineering is defended against Deutsch's objections.
\end{abstract}

Keywords Conceptual engineering Implementation challenge $\cdot$ Semantic meaning $\cdot$ Speaker-meaning $\cdot$ Max Deutsch

\section{Deutsch's dilemma}

Conceptual engineering is on the rise. Almost every month, new papers are published, proposing to engineer this or that concept; and theorizing about conceptual engineering is now an established and growing area of metaphilosophy. While the reception of conceptual engineering has mostly been friendly, even enthusiastic, there are also a few critical voices. One of them is Max Deutsch, who

Steffen Koch

steffen.koch@rub.de

1 Ruhr-Universität Bochum, Institut für Philosophie II, Universitätsstraße 150, 44801 Bochum, Germany 
has recently argued that conceptual engineering does not deserve the attention it currently receives; for upon scrutiny, it does not provide philosophers with the implementable and underappreciated methodological tool that its advocates claim it does (Deutsch 2020). This paper responds to Deutsch's critical take on conceptual engineering.

According to Deutsch, advocates of conceptual engineering are stuck in a dilemma. The two horns of this dilemma stem from two different ways of engaging in conceptual engineering. The first is to introduce new concepts; the second is to revise concepts that are already being used. Let us call these activities 'conceptual construction' and 'conceptual re-engineering' respectively. Deutsch argues that neither conceptual construction nor conceptual re-engineering are feasible and underexplored philosophical methods. But, according to Deutsch, this conclusion is less worrisome than it may first seem, because the typical rationale for the value of conceptual engineering is mistaken anyway.

Let me begin with a caveat. As of yet, there is no agreement about what the objects of conceptual engineering are, and various options are on the table. I develop and defend one of these options elsewhere (Koch 2020). For present purposes, however, I follow Deutsch in assuming that conceptual engineering targets pairs of words and meanings. Construed in this way, conceptual construction boils down to the introduction of new (technical) vocabulary with stipulated meanings (e.g. 'supervenience' or 'grounding'), and conceptual re-engineering amounts to the stipulation of new meanings for terms already in use (e.g. Haslanger's work on 'woman', 'man', and 'race'). ${ }^{1}$

A key ingredient of Deutsch's dilemma is the distinction between speakermeaning and semantic meaning (Grice 1989). The semantic meanings of expressions are the literal meanings they have in a given language. This type of meaning is relatively stable across different situations. It is roughly what dictionaries aim to capture by stating definitions. ${ }^{2}$ Unlike semantic meanings, speaker meanings are not stable, and they are not associated with terms, but with speech acts. The speaker-meaning of a speech act is, roughly, what you intend to communicate by a speech act in a given instance. Semantic meaning and speaker meaning often come apart. Pinder (2019) mentions the example of Sophie, who opens the curtains on a miserable and rainy day and exclaims with faux enthusiasm 'It's another beautiful day!' (p. 12). What Sophie speaker-means is that it is another miserable day; but what her assertion semantically means is that it is another beautiful day.

The first horn of Deutsch's dilemma focuses on conceptual re-engineering, i.e. attempting to revise the meaning of an existing term. Bearing in mind the distinction between speaker-meaning and semantic meaning, such attempts can aim to revise

\footnotetext{
${ }^{1}$ Deutsch mentions a third construal of conceptual engineering: the attempt to stipulate meaning additions for existing terms, e.g. when the law defines an 'adult' as someone over the age of 18. But since Deutsch argues that this ultimately reduces to what I've called 'conceptual construction', I set it aside for now. We will return to this point below.

${ }^{2}$ Note, however, that semantic externalists like Deutsch do not take semantic meanings to be constituted by definitions or other types of descriptive content.
} 
either semantic meaning or speaker-meaning. Suppose conceptual engineers aim to revise semantic meaning. If this is what they aim to do, then they face a severe implementation challenge, for the main tools they have at their disposal-namely, stipulating what they and others shall mean by a term, and intending to use the term in the way suggested-do not have the power to change semantic meaning. Deutsch uses the example of 'dog' to make this point:

Suppose I publish a paper in which I declare that, henceforth, and for all time, 'dog' shall mean cats. What effect could this declaration have? Perhaps, afterwards, I and my followers (loyal and steadfast as they are) will now go around speaker-referring to cats with our uses of 'dog'. Clearly, though, neither my nor my followers' intentions or behavior will do much of anything to affect the semantic meaning and reference of the English term, 'dog'. Even if my explicit intention is to change the semantic meaning and reference of 'dog', it seems I am powerless to actually do so. Importantly, even if groups of other speakers start getting in on the act-my followers' followers, their followers, etc.- the only result will be a change in what certain groups of speakers now speakermean by 'dog' (along with a fair bit of miscommunication with others). 'Dog' will go on semantically meaning and referring to what it always has (p. 6).

Rather uncontroversially, Deutsch notes that neither stipulation alone nor the intention of a single speaker are sufficient means of changing semantic meanings. More controversially, Deutsch thinks that even large groups ("my followers' followers, their followers, etc.") are powerless to change semantic meanings. Regardless of their efforts, the term in question will semantically mean and refer "to what it always has".

Deutsch concedes that semantic meaning and reference can and do change over time. But since we do not know what, in addition to stipulation and one's motivation to bring about meaning change, is required to actually make it happen, we can hardly bring it about intentionally. We do not know how many people have to join the effort, or for how long they have to use the term in accordance with the stipulation, or which further steps are necessary. Deutsch concludes that conceptual engineers who aim to change semantic meaning "owe us an account of how they can actually succeed in doing so" (p. 7).

Deutsch admits that we can use stipulations to express what we shall speakermean by a term. So, if conceptual re-engineering targets speaker-meaning, the implementation challenge does not arise. However, Deutsch argues that if conceptual re-engineering were to boil down to stipulating speaker-meanings, then the whole enterprise of conceptual engineering would trivialize: "[Re-engineering speaker-meaning] seems like a rather trivial and easy thing to do. Surely it is not the sort of thing the exciting terminology of 'conceptual engineering' was designed to describe" (p. 7). We can call this the trivialization challenge.

The intermediate result, i.e. the first horn of the dilemma, is the following. If conceptual re-engineering aims to "effect genuine semantic changes in an existing term by mere stipulation[, it] seem[s] bound to fail" (p. 10). If, on the other hand, it aims to stipulate speaker-meaning, then "it is not clear that [it] deserves to be called 
'conceptual engineering', or that [it] represents a worthwhile, fruitful method of philosophizing" (ibid.).

The second horn arises for conceptual engineering in the sense of conceptual construction. Deutsch admits that stipulation has the power to create new semantic meanings if the term in question does not have a fixed semantic meaning already. So again, there is no implementation challenge to conceptual construction. But Deutsch argues that it faces a version of the trivialization challenge. In cases of conceptual construction, the hard part is not implementation, but rather identifying an interesting phenomenon or relation, such that introducing a new term for it reaps epistemic benefits. Deutsch holds that philosophy, just like any other theoretical discipline, can and does often benefit from the introduction of new technical terms. 'Supervenience', 'implicature', 'rigid designator' and 'safety' are cases in point. The problem is rather that this possibility is too obvious, and too much in line with traditional philosophical practice, to be an interestingly new and revisionary approach to philosophy. Thus, Deutsch asks rhetorically: "[D]id philosophers really need to be told any of this? [...] Have defenders of conceptual engineering reminded philosophers of something they forgot, or perhaps never knew, namely that, sometimes, there is a need for technical terms in philosophy?" (p. 12). The obvious answer, Deutsch suggests, is 'no'.

If Deutsch is right, then there is no version of conceptual engineering that warrants the enthusiasm of its advocates. For this enthusiasm to be warranted, Deutsch assumes, conceptual engineering would have to be a philosophical method that is feasible, valuable, and previously neglected at the same time. But according to Deutsch, neither construal of conceptual engineering satisfies all of these conditions simultaneously. Deutsch concludes that "conceptual engineering, with the exception of the introduction of useful technical terminology [which is trivial], doesn't belong in the philosopher's tool box" (p. 22).

\section{Resolving the dilemma}

In what follows, I will show that Deutsch's dilemma for conceptual engineering does not arise. In doing so, I will mainly focus on conceptual re-engineering, for two reasons. First, this is the kind of conceptual engineering that most of the contemporary discussion focusses on. Second, I partly agree with Deutsch that conceptual construction is less new and exciting than conceptual re-engineering. Conceptual engineering would indeed lose much of its appeal if it were nothing but the recommendation that philosophers introduce new technical vocabulary where necessary. I suspect that most conceptual engineers would agree. So, my strategy will be to grant Deutsch the second horn of the dilemma but to reject the first. ${ }^{3}$

\footnotetext{
3 This said, the debate between Carnap and Strawson shows that there is room for a non-trivial debate over whether philosophers should focus more on answering typical 'what is $x$ ?' questions, or instead focus on constructing new technical terms to be employed, e.g., in science and logic. Whereas Carnap views the terms of ordinary language as imprecise tools, to be replaced where necessary by philosophers, Strawson takes them to be of independent interest, and therefore advocates a conception of philosophy on which it
} 
Recall that the first horn of Deutsch's dilemma is a dilemma in itself. The charge is that conceptual re-engineering is either infeasible or trivial, depending on whether it is construed in terms of semantic meaning or speaker-meaning.

My first objection to Deutsch is that this construal of the options is a false dichotomy. It's not that we can either aim to change semantic meanings, or else settle for individual-level speaker-meaning. There is room for a plausible, implementable and non-trivial project that lies between the two, namely, to convince other members of one's group to use an existing term in a new way. In many areas of philosophy, and in academic disciplines in general, it is important that the participants in a debate 'speak the same language'. The fact that their terms have similar or identical semantic meanings is not enough. It is also important that their communicative intentions are aligned in the right way. In other words, it is important for the participants in a debate to understand what others intend to communicate when they use certain expressions. The process of mutual understanding is facilitated enormously if the participants share their communicative intentions. Since certain speaker-meanings are less conducive to successful philosophical or academic work than others-an assumption that conceptual engineers typically make, and which will be scrutinized below - the project of improving what a group of researchers speakermeans by its key terms becomes both salient and important. For this reason, the speaker-meaning construal of conceptual re-engineering need not have the trivializing tendencies alleged by Deutsch. ${ }^{4}$

If this is right, then conceptually engineering group-level speaker-meanings is an activity that is both important and implementable. Now, perhaps Deutsch would grant this much, but object that this activity is simply not exciting and new enough to be called 'conceptual engineering' or to deserve its current attention. ${ }^{5}$ Deutsch raises this concern when he discusses the hypothesis that conceptual engineering amounts to 'stipulative additions', by which he means the addition of new meanings to terms already in use. Stipulative additions are very close to the proposal currently on offer. And while Deutsch concedes that these do play a legitimate role in philosophy and elsewhere, he argues that if conceptual engineering were construed as the attempt to stipulate additional meanings, then there would be "nothing particularly new or neglected about [it]" (p. 14). ${ }^{6}$

Footnote 3 continued

is the philosopher's main job to elucidate them (cf. Carnap 1950/1971, 1963/1991; Strawson 1963/1991; see Koch ms for discussion). Unlike what is suggested by Carnap and Deutsch, conceptual construction need not be limited to technical terms, but might also be put in the service of society at large. See e.g. Miranda Fricker's (2007) discussion of 'sexual harassment'. Thanks to an anonymous reviewer for suggesting this example.

${ }^{4}$ See Pinder (2019) for a thoroughgoing defense of the speaker-meaning picture of conceptual reengineering.

5 Thanks to an anonymous reviewer for suggesting this rejoinder.

6 Deutsch also argues that there is only a "superficial difference" (p. 14) between what he calls 'stipulative addition' and what I earlier identified as 'conceptual construction'. I disagree, for I take it to be an important difference between the two that conceptual construction introduces new terms, whereas stipulative addition attaches new meanings to old terms. There is thus a revisionary element to stipulative additions-even if just at the level of speaker-meaning - that is absent from conceptual construction. 
How new and neglected does conceptual engineering have to be for the hype to be justified? Many conceptual engineers happily concede that conceptual engineering is and has long been practiced throughout philosophy (cf. Cappelen 2018, ch. 2; Plunkett 2015; Sawyer 2020; Thomasson 2020). According to them, what is new is not that it is being done, but that it is being recognized and theorized. Moreover, scrutinizing the meanings of one's terms and engineering new group-level speakermeanings in the way suggested above has arguably not taken center stage in mainstream analytical philosophy. So while conceptual engineering, in the sense currently at issue, might not be entirely new or altogether neglected, one might still hold that it deserves more attention than it has received thus far.

Putting this aside, I agree with Deutsch that conceptual engineers sometimes have higher ambitions, i.e. they want to change semantic meanings rather than speaker-meanings. I also agree that changing semantic meaning is difficult, and that it cannot be achieved by mere stipulation. The crucial question is whether it is so difficult that conceptual engineers should not even aim to do it-and here I do not share Deutsch's pessimism.

As outlined in the previous section, Deutsch's implementation challenge has two components. The first is that the obvious tools of conceptual engineers are ineffective when it comes to semantic meaning change. The second is that we are not in a position to know what else is necessary to bring about semantic meaning change. Deutsch argues that conceptual engineers carry the burden of proof: those who aim to revise semantic meanings "owe us an account of how they can actually succeed in doing so" (p. 7). In what follows, I will sketch one such account, defend it against Deutsch's objections, and show that it renders conceptual engineering feasible.

Since the first part of Deutsch's skepticism questions whether it is within our control to bring about meaning change, it is worth reflecting on different notions of control. In Koch (2018), I make two distinctions concerning control that are relevant in this context. The first concerns who we ascribe control to, i.e. individuals or collectives. The second is between immediate and long-range control. Unlike immediate control, exercising long-range control requires engaging in long-term action. Many if not most of our dearest goals, both as individuals and as collectives, are only within our long-range control. Reducing world poverty, increasing social justice, or lowering $\mathrm{CO}_{2}$ emissions, for example, are merely within our (collective) long-range control; but this does not undermine our commitment or even our obligation to pursue them.

What does it take for a term to change reference? Although the early externalists primarily aimed to answer an opposing question, namely, how a term can have stable reference across different times and speakers, this question received some attention in the seventies and early eighties. Most notably, Gareth Evans and Michael Devitt took it to be a key desideratum of causal theories of reference that they also explain and account for the possibility of reference change. ${ }^{7}$ The accounts

\footnotetext{
7 In Naming and Necessity (1970/1981), Kripke also acknowledges the reality of reference change, but proposes to leave a full treatment for future work (p. 163).
} 
that both of these authors ended up endorsing go roughly as follows: The reference of a (kind) term $t$ is the (kind of) entity that causally grounds those of a speaker's beliefs that dispose her to use $t$ (Evans 1973; Devitt 1981). ${ }^{8}$ Thus, if it is experiences with instances of the kind dog that causally ground those beliefs of mine that dispose me to utter 'dog', then 'dog' refers to dogs. Evans and Devitt note that this version of the causal theory of reference, here only roughly sketched, nicely accommodates cases of reference change. When Marco Polo started applying 'Madagascar' to the East African island rather than to Mogadishu (a part of the African mainland), he initially (unknowingly) referred to Mogadishu, because most of the beliefs that disposed him to utter 'Madagascar' were causally grounded in Mogadishu. But this changed over time. New beliefs that were grounded in Madagascar, the island, were acquired, old beliefs faded, and preserved beliefs acquired new sustaining grounds. Today, long after Marco Polo's endeavors, 'Madagascar' undoubtedly refers to the island.

This Evans-Devitt-style metasemantics allows for collective long-range control over reference change (Koch 2018). As people apply an existing term to a new kind of entity, they gather beliefs that have the new kind as their causal ground. If, for instance, I tell you about an observation I made about (what are now called) dogs, but I use the term 'cat' instead of 'dog' in my testimony, then a belief about dogs will enter your dispositional profile of 'cats'. If this happens again and again, there will eventually come a time when your dispositional profile of 'cat' consists mainly of beliefs about dogs. When that point is reached, what you refer to by 'cat' will switch from cats to dogs. There is a range of possible views about what happens in the meantime. According to Devitt (1981), 'cat', in your mouth, will refer partially to cats and partially to dogs, depending on the overall proportion of cats and dogs in your dispositional profile (p. 193). Evans (1973), in contrast, seems more inclined to think that there is a threshold concerning which causal source is 'dominant' (pp. 200-201) such that, once it is crossed, reference switches from one kind to another. Regardless of these details, both views entail that larger collectives, e.g. linguistic communities, can exercise collective long-range control in order to bring about reference change.

Here we have, at least in rough sketch form, an externalist account of how conceptual engineers can pursue their goal of changing semantic meaning. In short: They can use the term in question as if it already had the new meaning, and try to convince as many other people as possible to follow their lead. If they reach enough people and remain consistent, then this will eventually change the term's semantic meaning - either bit by bit, as suggested by Devitt, or once a certain threshold is crossed, as suggested by Evans.

I anticipate two kinds of objections. You might think that Evans and Devitt's underlying view is false. Like any other metasemantic view, the Evans-Devitt view is not uncontroversial, and the general idea sketched above undoubtedly needs refinement. It is beyond the scope of this paper to properly defend this view. But notice that all that is really needed to establish the feasibility of intentional meaning

\footnotetext{
${ }_{8}^{8}$ I should note that both authors add numerous qualifications to this view, but these need not concern us here.
} 
change is the idea that if terms are used in new ways by many speakers over long periods of time, then their semantic meanings will eventually change. Evans and Devitt offer specific accounts of why and how this happens that you might object to for one reason or another. But the general point here should be rather uncontroversial, even for externalists. If one denies that even radical changes of use-by however large a group of people, over however long a time period-will change semantic meanings, one is in effect denying that there is any connection between use and meaning. Few philosophers, even staunch externalists, will be happy to endorse this conclusion.

You might also think that the Evans-Devitt view is fine in itself, while maintaining that the power it gives us over semantic meanings is insufficient to block Deutsch's implementation challenge. This line is taken by Deutsch, who criticizes my view as follows:

[T]he problem with Koch's picture, even granting an Evans-style metasemantics, is that there is no telling, in advance, that a plan to get large numbers of speakers to use $t$ as if it refers to $x$ will actually turn $x$ into the dominant causal source of the attitudes speakers express when using $t$. People can make widespread mistakes, for example, using $t$ even in relation to things that are not $x$ 's, despite the intention to use $t$ only in relation to $x$ 's (Deutsch 2020, p. 20).

Deutsch is surely right that given the Evans-Devitt-style metasemantics sketched above, there is no guarantee that a conceptual engineering project will be successful. It is far from trivial to reach or convince the required number of people. Moreover, even if we did convince the required number of people, other things can go wrong. We might, for example, be in massive error about what counts as an $x$, and thus unintentionally end up applying $t$ to things other than $x \mathrm{~s}$.

However, I am not convinced that either of these obstacles gives rise to an implementation challenge that is specific to conceptual engineering. By contrast, I take it that almost any kind of worthwhile long-term project faces these obstacles (and potentially others), but that this does not and should not stop us from pursuing them. Individuals engage in all sorts of long-term activities without having any guarantee of success or antecedent knowledge about their outcomes. Think of activities like obtaining a university degree, pursuing a career, or getting married. As collectives, we negotiate peace treaties with other nations, make plans to reduce $\mathrm{CO}_{2}$ emissions, and to improve our education systems. Arguably, we are morally obliged to engage in some of the activities on this list—-despite the fact that our only hope of achieving them is by exercising collective long-range control, despite success not being guaranteed, and despite our lack of antecedent knowledge of whether we will succeed. The problem with Deutsch's objection, then, is that it runs the risk of overgeneralizing to many human activities and projects that are uncontroversially worthwhile.

In light of this observation, the challenge for Deutsch is to specify some relevant difference between conceptual engineering and other projects such as obtaining a university degree, reducing $\mathrm{CO}_{2}$ emissions, or improving education systems-a difference that explains why the obstacles we face in achieving the latter do not 
undermine our commitments or even our obligations to pursue them, whereas similar obstacles do undermine any moral or methodological commitment to conceptual engineering. As I've argued above, systematic differences concerning their feasibility cannot serve as the explanans that is needed here.

\section{The conceptual engineer's rationale}

If the explanans is not feasibility, then perhaps it is importance. Perhaps all these projects are equally feasible, but unlike the rest of them, conceptual engineering just isn't worth the effort. Indeed, Deutsch does not take conceptual engineering to be particularly important. This is because, according to him, the standard rationale for the importance of conceptual engineering, i.e. that many of our terms and concepts are defective and in need of repair, is mistaken. In this final section, I will defend this rationale against Deutsch's objection. ${ }^{9}$

Deutsch launches the following argument against the conceptual engineer's rationale:

This account of the value of conceptual engineering clearly depends on the view that many of our terms, including many of our philosophical terms, such as 'knowledge', 'free action', and 'woman', are semantically defective. Are these terms semantically defective? Not if their purpose is to allow us to speak of, and communicate about, things like knowledge, free action, and women. A good way to speak of, and communicate about, knowledge, free action, and women is to use terms that semantically refer to these things, and the terms that semantically refer to these things include 'knowledge', 'free action', and 'woman'. So, the usual rationale for engaging in conceptual engineering is a bad rationale: since our terms are not, in fact, defective, relative to the purpose of using them to speak of their semantic referents, there is no need, and no value, in trying to improve them (Ibid., p. 21).

In brief, the argument seems to be this. According to the conceptual engineer's rationale, many of our concepts are semantically defective. However, if they were, then they would not allow us to use them to talk and think about their referents. But they clearly do allow this. We can use 'knowledge' to talk about knowledge, we can use 'free will' to talk about free will, and so on. So, the conceptual engineer's rationale must be mistaken.

I would like to raise three objections to this argument. ${ }^{10}$ First of all, the argument, as it stands, begs the question against conceptual engineers who think that some (or many) of our concepts are semantically deficient. Conceptual engineers have done two things to establish the occurrence of semantic deficiencies. They have provided general metasemantic and psychological accounts of why and how conceptual

\footnotetext{
9 Note that giving a full-blown argument for the importance of conceptual engineering and defending it against all types of possible objections goes beyond the scope of this paper. Instead, I will pursue the more modest goal of showing that Deutsch's objections to this rationale are not decisive.

${ }^{10}$ I thank an anonymous reviewer for helping me to structure this section in the present way.
} 
deficiencies arise, and they have offered numerous concrete case studies. Scharp (2013), for instance, provides a detailed account of inconsistent concepts, arguing that they are based on inconsistencies in their constitutive principles (ch. 2). Cappelen (2018) rejects the idea that concepts consist of constitutive principles, but he shows that even an externalist metasemantics has room for semantic deficiencies (ch. 8), e.g. when the description used to fix reference in the introduction of a term involves incoherent or inconsistent conditions (as in Kripke's framework), when people's causal source for a term involves numerous (kinds of) entities (as in an Evans-Devitt-style framework), or when deference relations are circular (as in Burge's framework). Machery (2017), who defends a psychological approach to conceptual engineering, demonstrates that concepts can be deficient by disposing us to draw unreliable inferences (ch. 7.7). As all the above authors argue, we have every reason to believe that if some of our concepts or terms are deficient, then many of them are. There is simply no good reason to believe that most of our concepts are magically shielded from these deficiencies (cf. Cappelen 2020).

Conceptual engineers have also provided detailed case studies of the general deficiencies just mentioned. For instance, Scharp (2013) gives a book-length defense of the view that our concept of 'truth' is inconsistent in the way described above, thus giving rise to the famous liar paradox. Similarly, Fassio and McKenna (2015) argue that our concept of knowledge incorporates inconsistent platitudes, resulting in indeterminate application conditions. Griffiths et al. (2009) provide empirical data indicating that people's concept of innateness disposes them to draw various invalid inferences between the universality, the plasticity, and the function of a trait.

If Deutsch is to object to the idea of semantic deficiencies, then he needs to show that the above accounts are either based on misconceptions, or at any rate unlikely to be instantiated in the actual world. But there is no engagement with any of these accounts in Deutsch's paper. Nor is there any detailed discussion of relevant case studies that would prove them to be ill-motivated.

Instead, Deutsch argues that terms of philosophical significance such as 'knowledge' or 'free will' seem to be in good enough shape for us to use them to talk about their referents, i.e. knowledge and free will. Note, however, that conceptual engineers who think that, e.g., 'knowledge' and 'free will' are semantically defective, need not deny that these terms are perfectly apt when used in most ordinary situations. Scharp (2013) explicitly notes that even inconsistent concepts need not be empty, and that they can be employed in most ordinary situations (p. 37). The inconsistency of our truth concept, for example, does not make this concept entirely useless. It merely crops up when we try to apply it to liar sentences. Likewise, Fassio and McKenna (2015) do not claim that 'knowledge' cannot be applied to many paradigm instances of knowledge. The problem is rather that the concept has unclear application conditions in a certain type of special case. None of this is to deny that concepts such as 'truth' and 'knowledge' can be used to communicate successfully in many other contexts. Deutsch's observation about the apparent non-defectiveness of these concepts does not, therefore, undermine the conceptual engineer's rationale. 
My second objection to Deutsch is that he neglects the importance of conceptual deficiencies that are not semantic in nature. Consider how Sally Haslanger, a leading conceptual engineer, describes her project of ameliorating gender and race terms: it is the attempt to identify how "we might usefully revise what we mean [by these terms] for certain theoretical and political purposes" (Haslanger 2000, p. 34). For Haslanger, these are feminist purposes; in particular, the purposes of identifying and remediating sex-based oppression. According to Haslanger, revising our gender concepts in the suggested way helps us to identify sex-based oppression by making it the focal point of our very gender concepts; and this helps us to remediate sexbased oppression because it contributes to an emancipatory process. This argument has little to do with whether our ordinary terms 'man' and 'woman' are semantically defective. As far as Haslanger is concerned, they might not be.

Deutsch probably thinks that Haslanger is mistaken. But there is no argument in his paper that undermines her rationale. Again, it seems that either Deutsch would have to provide general reasons for why the type of rationale that is endorsed by Haslanger (and, in amended versions, repeated in Dembroff's 2016 work on 'sexual orientation', Kania's 2012 work on 'pornography', and Manne's 2018 work on 'misogyny') is mistaken or unlikely to be instantiated in the actual world, or he would have to show that the central cases motivated by this rationale, e.g. Haslanger's cases of race and gender concepts, do not withstand scrutiny, and then inductively generalize this conclusion. However, Deutsch does neither of these. Instead, he reiterates that even politically relevant terms such as 'marriage' and 'immigrant' "are non-defective enough to allow us to use them to speak of marriage and immigrants" (p. 22). But conceptual engineers of the Haslangerian type do not deny that these terms are semantically non-defective in the sense of referring to whatever they refer to. Deutsch's objection seems to be based on a mischaracterization of their rationale. ${ }^{11}$

Lastly, it is worth mentioning that not all conceptual engineers follow the rationale described by Deutsch. Mona Simion (2018), for example, argues that there is "little reason [...] to restrict the project [of conceptual engineering] to remedying deficient representational devices, rather than go on a more ambitious quest: conceptual improvement" (p. 915). On Simion's picture, concepts ought to be improved primarily along an epistemic dimension, as they otherwise risk a wrongkinds-of-reasons fallacy. This epistemic dimension concerns how well a concept assists us in the pursuit of knowledge. Those sympathetic to Simion's picture might therefore find conceptual engineering valuable even if most of our concepts are nondeficient. There is thus a viable route into conceptual engineering that remains completely untouched by Deutsch's claim that most (or all) of our concepts are, in fact, non-deficient.

If the above considerations are on the right track, then Deutsch's objection to the standard rationale for conceptual engineering fails. But if conceptual engineering is as important as this rationale makes it out to be, then there is no asymmetry between

\footnotetext{
11 It is important to stress that Deutsch nowhere denies that the goal of promoting social justice is an important one; quite the contrary. His point is just that conceptual engineering has little hope of contributing to this admirable goal.
} 
conceptual engineering and other normative enterprises. Conceptual deficiencies give us good reasons to repair our concepts, just as other shortcomings-e.g. those concerning global justice_-give us reasons to 'repair' our societies or our ways of acting in the world.

\section{Conclusion}

Deutsch argues that conceptual engineering is trapped in a dilemma, since both of its varieties-conceptual re-engineering and conceptual construction-are either infeasible or trivial. I have argued that this dilemma does not arise. There is a plausible, feasible and non-trivial project of influencing what the relevant individuals in one's community speaker-mean by certain expressions. Moreover, even the more ambitious project of changing semantic meanings is just as feasible as other human endeavors whose importance is less controversial. Lastly, I have argued that the standard rationale for the importance of conceptual engineering, i.e. that many concepts are defective and in need of repair, withstands Deutsch's objections.

Acknowledgements My work on this paper was supported by a Grant of Deutsche Forschungsgemeinschaft for the Emmy Noether Independent Junior Research Group Experimental Philosophy and the Method of Cases: Theoretical Foundations, Responses, and Alternatives (EXTRA), Project Number 391304769. I thank Mirela Fuš, Joachim Horvath, Sigurd Jorem, Mark Pinder, and two anonymous reviewers of Philosophical Studies for comments on earlier versions of this paper.

Funding Open Access funding enabled and organized by Projekt DEAL.

Open Access This article is licensed under a Creative Commons Attribution 4.0 International License, which permits use, sharing, adaptation, distribution and reproduction in any medium or format, as long as you give appropriate credit to the original author(s) and the source, provide a link to the Creative Commons licence, and indicate if changes were made. The images or other third party material in this article are included in the article's Creative Commons licence, unless indicated otherwise in a credit line to the material. If material is not included in the article's Creative Commons licence and your intended use is not permitted by statutory regulation or exceeds the permitted use, you will need to obtain permission directly from the copyright holder. To view a copy of this licence, visit http:// creativecommons.org/licenses/by/4.0/.

\section{References}

Cappelen, H. (2018). Fixing language. An essay on the foundations of conceptual engineering. Oxford: Oxford University Press.

Cappelen, H. (2020). Conceptual engineering. The master argument. In H. Cappelen, D. Plunkett, \& A. Burgess (Eds.), Conceptual engineering and conceptual ethics. Oxford: Oxford University Press.

Carnap, R. (1950/1971). Logical foundations of probability (2nd ed.). Chicago, IL: Univ. of Chicago Press.

Carnap, R. (1963/1991). P. F. Strawson on linguistic naturalism. In P. A. Schilpp (Ed.), The philosophy of Rudolf Carnap. La Salle/IL: Open Court, pp. 933-943.

Dembroff, R. (2016). What is sexual orientation? Philosophers' Imprint, 16, 1-27. 
Deutsch, M. (2020). Speaker's reference, stipulation, and a dilemma for conceptual engineers. In Philosophical studies, online-first. https://doi.org/10.1007/s11098-020-01416-z.

Devitt, M. (1981). Designation. New York, NY: Columbia University Press.

Evans, G. (1973). The causal theory of names. Aristotelian Society Supplementary, 47, 187-225. https:// doi.org/10.1093/aristoteliansupp/47.1.187.

Fassio, D., \& McKenna, R. (2015). Revisionary epistemology. Inquiry, 58(7-8), 755-779.

Fricker, M. (2007). Epistemic injustice. Power and the ethics of knowing. Oxford: Oxford University Press.

Grice, H. P. (1989). Studies in the way of words. Cambridge, MA: Harvard University Press.

Griffiths, P. E., Machery, E., \& Linquist, S. (2009). The vernacular concept of innateness. Mind and Language, 24, 605-630.

Haslanger, S. A. (2000). Gender and race: (What) are they? (What) Do we want them to be? Nous, 34, 31-55. https://doi.org/10.1111/0029-4624.00201.

Kania, A. (2012). Concepts of pornography: Aesthetics, feminism, and methodology. In H. Maes \& J. Levinson (Eds.), Art and pornography: Philosophical essays. Oxford: Oxford University Press.

Koch, S. (2018). The externalist challenge to conceptual engineering. Synthese, online-first. https://doi. org/10.1007/s11229-018-02007-6.

Koch, S. (ms). Why conceptual engineers should not worry about topics.

Koch, S. (2020). Engineering what? On concepts in conceptual engineering. Synthese, online-first.

Kripke, S. (1970/1981). Naming and necessity. Oxford: Basil Blackwell Ltd.

Machery, E. (2017). Philosophy within its proper bounds. Oxford: Oxford University Press.

Manne, K. (2018). Down girl. The logic of misogyny. New York, NY: Oxford University Press.

Pinder, M. (2019). Conceptual engineering, metasemantic externalism and speaker-meaning. Mind, online-first. https://doi.org/10.1093/mind/fzz069.

Plunkett, D. (2015). Which concepts should we use? Metalinguistic negotiations and the methodology of philosophy. Inquiry, 58(7-8), 828-874. https://doi.org/10.1080/0020174X.2015.1080184.

Sawyer, S. (2020). Truth and objectivity in conceptual engineering. Inquiry. https://doi.org/10.1080/ 0020174X.2020.1805708

Scharp, K. (2013). Replacing truth. Oxford: Oxford University Press.

Simion, M. (2018). The 'should' in conceptual engineering. Inquiry: An Interdisciplinary Journal of Philosophy, 61(8), 914-928.

Strawson, P. F. (1963/1991). Carnap's view on constructed systems versus natural languages in analytic philosophy: The two methods. In P. A. Schilpp (Ed.), The philosophy of Rudolf Carnap. La Salle/IL: Open Court, pp. 502-519.

Thomasson, A. L. (2020). A pragmatic method for conceptual ethics. In H. Cappelen, D. Plunkett, \& A. Burgess (Eds.), Conceptual engineering and conceptual ethics. Oxford: Oxford University Press.

Publisher's Note Springer Nature remains neutral with regard to jurisdictional claims in published maps and institutional affiliations. 